\title{
Article
}

\section{Copper-Containing Nanoparticles and Organic Complexes: Metal Reduction Triggers Rapid Cell Death via Oxidative Burst}

\author{
Sergey A. Tsymbal ${ }^{1, *(\mathbb{D}, \text { Anna A. Moiseeva }}{ }^{2}$, Nikol A. Agadzhanian ${ }^{1}$, Svetlana S. Efimova ${ }^{3}{ }^{(0)}$, \\ Alina A. Markova ${ }^{4,5}$, Dmitry A. Guk ${ }^{2}{ }^{(}$, Olga O. Krasnovskaya ${ }^{2}{ }^{\circledR}$, Victoria M. Alpatova ${ }^{5}{ }^{\circledR}$, \\ Andrei V. Zaitsev ${ }^{5}{ }^{\circledR}$, Anna V. Shibaeva ${ }^{4}{ }^{\circ}$, Victor V. Tatarskiy ${ }^{6}$, Marina S. Dukhinova ${ }^{1}$, \\ Valentina A. Ol'shevskaya ${ }^{5}$, Olga S. Ostroumova ${ }^{3}$, Elena K. Beloglazkina ${ }^{2,+}$ and Alexander A. Shtil ${ }^{2,7,+}$
}

check for updates

\section{Citation: Tsymbal, S.A.;}

Moiseeva, A.A.; Agadzhanian, N.A.; Efimova, S.S.; Markova, A.A.; Guk, D.A.; Krasnovskaya, O.O.; Alpatova, V.M.; Zaitsev, A.V.; Shibaeva, A.V.; et al. Copper-Containing Nanoparticles and Organic Complexes: Metal Reduction Triggers Rapid Cell Death via Oxidative Burst. Int. J. Mol. Sci. 2021, 22, 11065. https://doi.org/ $10.3390 /$ ijms 222011065

Academic Editor: Giorgio Pelosi

Received: 11 September 2021

Accepted: 7 October 2021

Published: 14 October 2021

Publisher's Note: MDPI stays neutral with regard to jurisdictional claims in published maps and institutional affiliations.

Copyright: (c) 2021 by the authors. Licensee MDPI, Basel, Switzerland. This article is an open access article distributed under the terms and conditions of the Creative Commons Attribution (CC BY) license (https:/ / creativecommons.org/licenses/by/ $4.0 /)$.
1 International Institute of Solution Chemistry of Advanced Materials and Technologies, ITMO University, 197101 Saint Petersburg, Russia; agadzhanian@scamt-itmo.ru (N.A.A.); dukhinova@scamt-itmo.ru (M.S.D.)

2 Department of Chemistry, Moscow State University, 119991 Moscow, Russia; moiseeva@org.chem.msu.ru (A.A.M.); dmh200949@gmail.com (D.A.G.); krasnovskayao@gmail.com (O.O.K.); beloglazki@mail.ru (E.K.B.); shtilaa@yahoo.com (A.A.S.)

3 Institute of Cytology, Russian Academy of Sciences, 194064 Saint Petersburg, Russia; efimova@incras.ru (S.S.E.); osostroumova@mail.ru (O.S.O.)

4 Emanuel Institute of Biochemical Physics, Russian Academy of Sciences, 119334 Moscow, Russia; alenmark25@gmail.com (A.A.M.); anna-shiba@mail.ru (A.V.S.)

5 A.N.Nesmeyanov Institute of Organoelement Compounds, Russian Academy of Sciences, 119334 Moscow, Russia; vika.alpatova@gmail.com (V.M.A.); porphyrin@yandex.ru (A.V.Z.); olshevsk@ineos.ac.ru (V.A.O.)

6 Institute of Gene Biology, Russian Academy of Sciences, 119334 Moscow, Russia; tatarskii@gmail.com

7 Blokhin National Medical Research Center of Oncology, 115478 Moscow, Russia

* Correspondence: zimbal@scamt-itmo.ru

$+\quad$ These authors share senior authorship.

Abstract: Copper-containing agents are promising antitumor pharmaceuticals due to the ability of the metal ion to react with biomolecules. In the current study, we demonstrate that inorganic $\mathrm{Cu}^{2+}$ in the form of oxide nanoparticles (NPs) or salts, as well as $\mathrm{Cu}$ ions in the context of organic complexes (oxidation states $+1,+1.5$ and +2 ), acquire significant cytotoxic potency ( $2-3$ orders of magnitude determined by $\mathrm{IC}_{50}$ values) in combinations with $\mathrm{N}$-acetylcysteine (NAC), cysteine, or ascorbate. In contrast, other divalent cations ( $\mathrm{Zn}, \mathrm{Fe}, \mathrm{Mo}$, and $\mathrm{Co}$ ) evoked no cytotoxicity with these combinations. CuO NPs $(0.1-1 \mu \mathrm{g} / \mathrm{mL})$ together with $1 \mathrm{mM}$ NAC triggered the formation of reactive oxygen species (ROS) within 2-6 h concomitantly with perturbation of the plasma membrane and caspase-independent cell death. Furthermore, NAC potently sensitized HCT116 colon carcinoma cells to $\mathrm{Cu}$-organic complexes in which the metal ion coordinated with 5-(2-pyridylmethylene)-2methylthio-imidazol-4-one or was present in the coordination sphere of the porphyrin macrocycle. The sensitization effect was detectable in a panel of mammalian tumor cell lines including the sublines with the determinants of chemotherapeutic drug resistance. The components of the combination were non-toxic if added separately. Electrochemical studies revealed that $\mathrm{Cu}$ cations underwent a stepwise reduction in the presence of NAC or ascorbate. This mechanism explains differential efficacy of individual $\mathrm{Cu}$-organic compounds in cell sensitization depending on the availability of $\mathrm{Cu}$ ions for reduction. In the presence of oxygen, $\mathrm{Cu}^{+1}$ complexes can generate a superoxide anion in a Fenton-like reaction $\mathrm{Cu}^{+1} \mathrm{~L}+\mathrm{O}_{2} \rightarrow \mathrm{O}_{2}^{-\cdot}+\mathrm{Cu}^{+2} \mathrm{~L}$, where $\mathrm{L}$ is the organic ligand. Studies on artificial lipid membranes showed that NAC interacted with negatively charged phospholipids, an effect that can facilitate the penetration of $\mathrm{CuO}$ NPs across the membranes. Thus, electrochemical modification of $\mathrm{Cu}$ ions and subsequent ROS generation, as well as direct interaction with membranes, represent the mechanisms of irreversible membrane damage and cell death in response to metal reduction in inorganic and organic $\mathrm{Cu}$-containing compounds.

Keywords: copper; reactive oxygen species; redox potential; drug resistance; cell death; tumor cells 


\section{Introduction}

Biocompatible agents containing copper in an inorganic form or in the context of metal-organic complexes are widely used in a variety of applications, largely as antibacterial and antifungal drugs, as well as in tumor treatment [1-5]. Copper oxide-based materials varying from sub- $10 \mathrm{~nm}$ to $40-60 \mathrm{~nm}$ (nanoparticles; NPs) and fine $(<10 \mu \mathrm{M})$ particles have demonstrated cytotoxicity against prokaryotic, yeast, mammalian cell lines and zebrafish embryos [6-9]. Coordination of $\mathrm{Cu}^{2+}$ or $\mathrm{Cu}^{1+}$ with complex organic scaffolds has yielded a number of perspective multi-targeting chemotypes with differential antitumor properties [10-14]. Thus, copper has proved its therapeutic value in a wide variety of applications.

Copper's unique sensitivity to the electrochemical status makes it particularly advantageous in situations where the biological effects are mechanistically dependent on reactive oxygen species (ROS) [15-19]. These studies have highlighted the opportunity of using $\mathrm{Cu}$-containing compounds alone or in combinations with conventional and novel agents. However, undesired toxicity of metal-containing drugs may limit their practical use. Zheng et al. [20] showed that the combination of $\mathrm{CuCl}_{2}$ and the antioxidant $\mathrm{N}$-acetylcysteine (NAC) induced a sizeable cytotoxic effect in cancer cell lines via the production of hydroperoxide. We are interested in determining whether $\mathrm{Cu}$-containing NPs or $\mathrm{Cu}$-organic complexes at non-toxic concentrations become potent against tumor cells if combined with non-toxic doses of NAC. Here, we demonstrate that these combinations triggered oxidative stress within the initial few hours followed by a complex mode of cell death regardless of the species and tissue origin. The effect of potentiation was limited to $\mathrm{Cu}$-containing compounds since NAC did not change the cytotoxicity of other tested metals. Importantly, electrochemical experiments showed that the ability to synergize with $\mathrm{Cu}$-containing compounds was attributed not to the antioxidant property of NAC but to a rapid reduction of $\mathrm{Cu}^{2+}$ to $\mathrm{Cu}^{1+}$. This mechanism was demonstrated for $\mathrm{CuO}$ NPs and $\mathrm{Cu}$-coordinated organic complexes and represents a means of copper reduction in inorganic and organic compounds as an approach to oxidative burst-mediated purge of pleural or abdominal cavities from metastatic tumor cells.

\section{Results}

\subsection{Synthesis and Characterization of $\mathrm{CuONPS}$}

$\mathrm{CuO}$ NPs were synthesized by the precipitation method [21]. The size of NPs determined by DLS was $80 \pm 20 \mathrm{~nm}$ (Figure 1); zeta potential was $+15 \pm 0.5 \mathrm{mV}$. The properties of magnetite and $\mathrm{ZnO}$ NPs have been reported by us [22].

\subsection{NAC Dramatically Increases the Cytotoxicity of $\mathrm{CuO} N P s$, Leading to Rapid Cell Death}

$\mathrm{CuO}$ NPs alone were moderately cytotoxic against a panel of mammalian cells as determined in MTT assays after $72 \mathrm{~h}$ exposure (Table 1). Given that the cytotoxicity of copper-containing compounds has been mechanistically attributed to ROS [23], we used non-toxic concentrations of NAC to modulate the efficacy of CuO NPs. Importantly, NAC $(1 \mathrm{mM})$ dramatically decreased cell survival in combination with $1 \mu \mathrm{g} / \mathrm{mL} \mathrm{CuO}$, the concentration that corresponds to $\sim \mathrm{IC}_{5}$ if added alone. Table 1 shows that the combination of $\mathrm{CuO}+\mathrm{NAC}$ caused remarkable sensitization of all tested cell lines, including the sublines with molecular determinants of antitumor drug resistance, such as MDR1/P-glycoprotein for K562/4 subline, anti-oxidative systems for SCOV3/CDDP subline, and an altered response to doxorubicin (Dox) due to p53 deficiency in the HCT116p53KO subline [24,25] (and the refs therein). Fold sensitization (determined as the ratio of $\mathrm{IC}_{50 \mathrm{CuO}} / \mathrm{IC}_{50 \mathrm{CuO}+\mathrm{NAC}}$ ) achieved values as high as $2-3$ orders of magnitude (Table 1 ). 


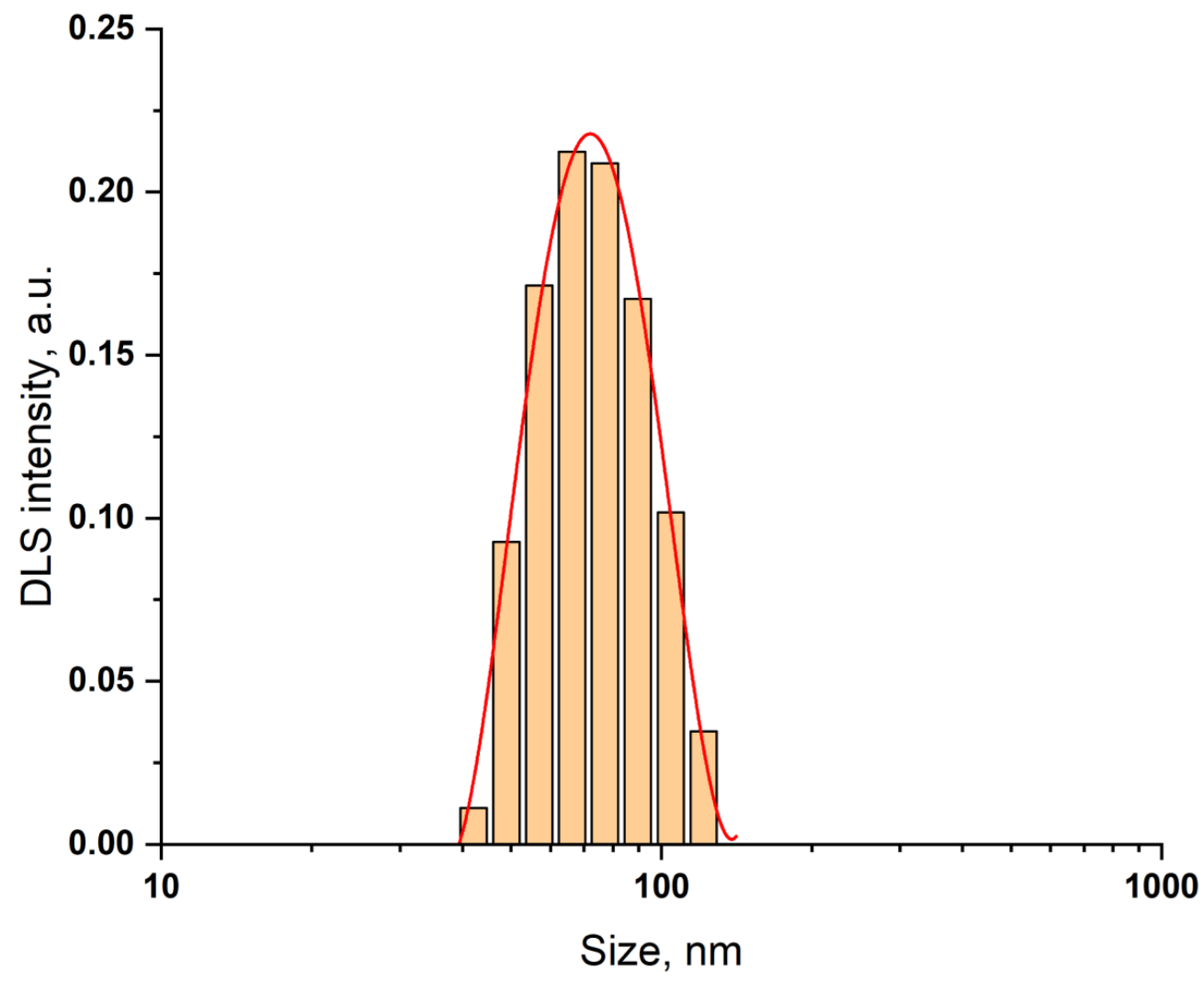

Figure 1. Size distribution of CuO NPs determined by DLS.

Table 1. NAC significantly enhances the cytotoxicity of CuO NPs.

\begin{tabular}{cccc}
\hline Cell Line & CuO & CuO + 1 mM NAC * & Fold Sensitization ** \\
\hline K562 & 8.5 & 0.01 & 850 \\
K562/4 & 16.2 & 0.01 & 1620 \\
MDA-MB-231 & 18.3 & 0.06 & 305 \\
HCT116 & 26.8 & 0.05 & 536 \\
HCT116p53KO & 15.2 & 0.04 & 380 \\
MOLM-6 & 5.7 & 0.02 & 285 \\
KU-812 & 7.0 & 0.02 & 350 \\
B16F10 & 17.6 & 0.06 & 293 \\
MCF-7 & 45.2 & 0.05 & 904 \\
SCOV-3 & 3.9 & 0.09 & 42 \\
SCOV-3/CDDP & 4.3 & 0.37 & 12 \\
hFB-hTERT6 & 9.1 & 0.02 & 455 \\
\hline
\end{tabular}

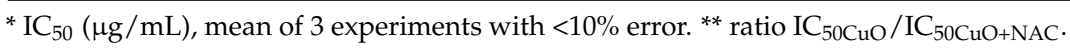

For studies of cell death mechanisms, we used $0.1-1 \mu \mathrm{g} / \mathrm{mL} \mathrm{CuO}$ and $1 \mathrm{mM}$ NAC. We investigated whether $\mathrm{CuO}+\mathrm{NAC}$ can trigger intracellular oxygen burst. Figure $2 \mathrm{~A}$ shows that $\mathrm{CuO}(1 \mu \mathrm{g} / \mathrm{mL})$ or NAC $(1 \mathrm{mM})$ alone evoked minor changes in fluorescence of the intracellular ROS probe DCFDA. In contrast, by $1 \mathrm{~h}$ of cell exposure to the combination of $\mathrm{CuO}$ and NAC, a statistically significant increase in DCFDA fluorescence was detectable; its maximum was reached by $2 \mathrm{~h}$ and remained sustained for at least $4 \mathrm{~h}$ (Figure 2A). These effects were paralleled by the time-dependent decrease in mitochondrial membrane electric potential (Figure 2B). Of note, a population with a lowered potential was detectable by $1 \mathrm{~h}$ of treatment of $\mathrm{K} 562$ cells with $\mathrm{CuO}+\mathrm{NAC}$ (not shown). 


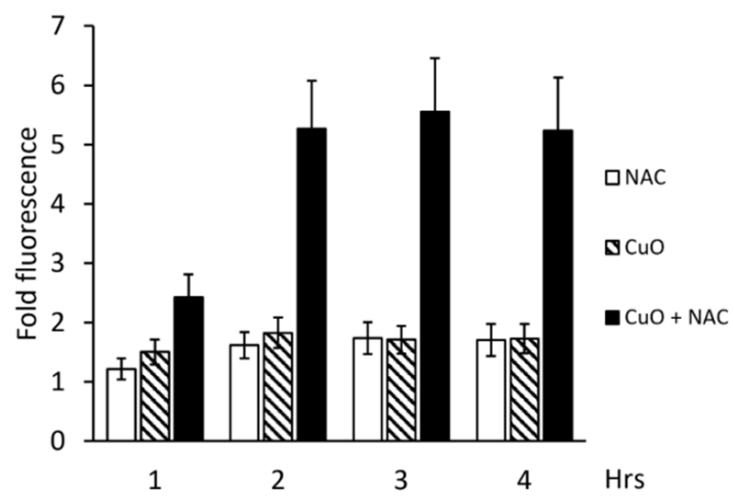

(A)
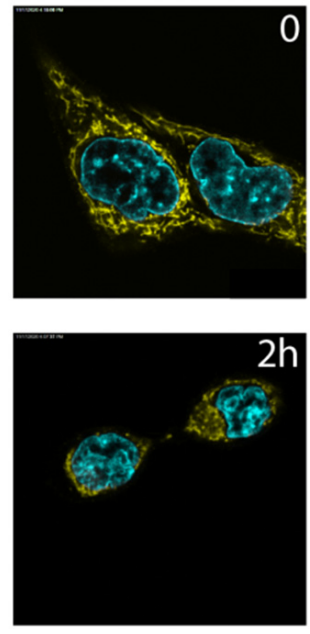
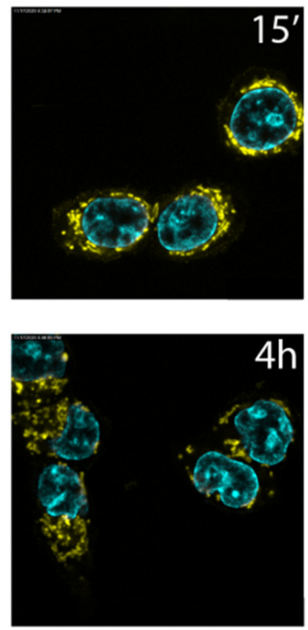

(C)

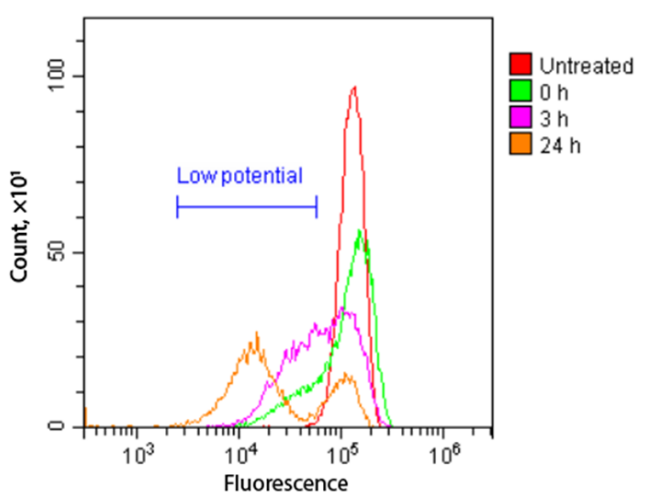

(B)
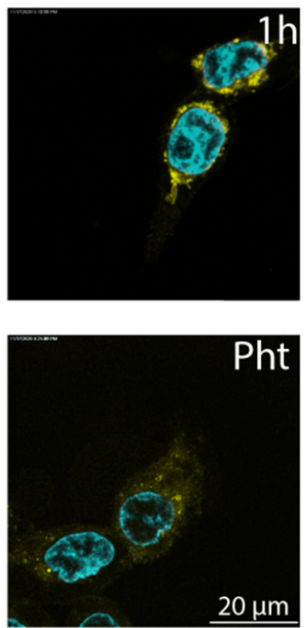

Figure 2. ROS burst and mitochondrial responses upon treatment with the combination of $1 \mu \mathrm{g} / \mathrm{mL} \mathrm{CuO} \mathrm{and} 1 \mathrm{mMNAC}$. (A,B): K562 cells; C: HCT116 cells. (A) Carboxy- $\mathrm{H}_{2}$ DCFDA $(5 \mu \mathrm{M})$ was added 30 min before the addition of the combination. Cell-associated fluorescence was measured in the FITC channel. Mean fluorescence intensity in untreated (no combination, carboxy $-\mathrm{H}_{2}$ DCFDA only) cells was taken as 1 . Data are mean+SD of three experiments. (B) Time-dependent decrease in mitochondrial electric potential (shown with the low potential marker). (C) Cells were labeled with the ROS indicator DHR 123 (yellow) and the nuclear stain Hoechst 33258 (blue) and analyzed by laser confocal microscopy. Pht, photolon.

To gain insight into the morphology of cell damage, we used the adherent HCT116 cell line. In untreated cells, the mitochondria stained with DHR 123 were visualized as definitive rod-shaped cytoplasmic structures (Figure 2C, upper left panel). In striking contrast, treatment with $\mathrm{CuO}$ NPs and NAC for only 15 min led to loss of the regular mitochondrial structure; during longer exposure to the combination, the mitochondria were detectable largely in the perinuclear area but less so across the cytoplasm (Figure 2C). By $4 \mathrm{~h}$, the cytoplasm with mitochondria and the nuclei were disintegrated. Interestingly, the shape of the nuclei as well as the chromatin density remained unaltered, indicating direct damage of the cytoplasmic content as a result of the combination of CuO NPs and NAC. For comparison, laser illumination of cells loaded with the reference compound photolon (Pht), a chlorin $\mathrm{e}_{6}$ derivative, led to dramatic damage of the cytoplasm (note the clusters of fragmented organelles and a significant decrease in DHR fluorescence in Figure 2C, bottom right panel). No mitochondrial changes were induced by either $\mathrm{CuO}$ or NAC alone (not shown).

ROS generation and the decrease in mitochondrial electric potential were concomitant with other parameters of cell death. Approximately $50 \%$ of K562 cells became annexin V positive by $4 \mathrm{~h}$ of treatment with $0.1 \mu \mathrm{g} / \mathrm{mL} \mathrm{CuO}+1 \mathrm{mM} \mathrm{NAC} \mathrm{(Figure} 3 \mathrm{~A}, \mathrm{~B}$ ). By $6 \mathrm{~h}$, a population of annexin V/PI double-positive cells was detectable; after $24 \mathrm{~h}$, virtually all 
cells were stained with annexin V and PI (Figure 3C,D). Interestingly, DNA fragmentation determined as the percentage of subG1 events was rather minor (Figure 3F), suggesting that, in $\mathrm{K} 562$ cells, death by the combination of $\mathrm{CuO}$ and NAC was largely associated with damage of the plasma membrane. This conclusion was supported by the lack of effect of the pan-caspase inhibitor z-VAD on annexin V/PI reactivity (Figure 3E).
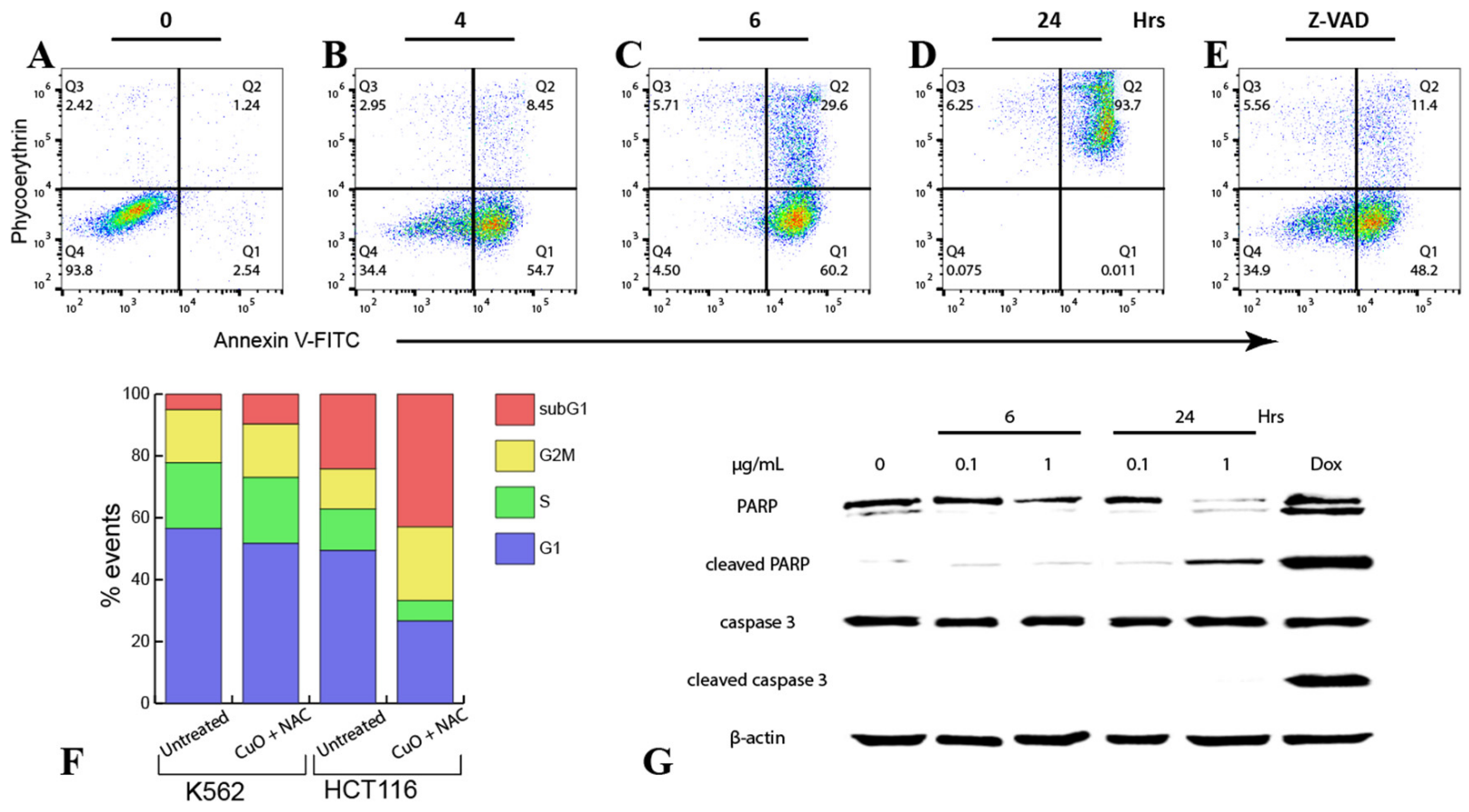

Figure 3. Death-associated events in cells treated with CuO NPs + NAC. The K562 (A-G) or HCT116 (F) cells were treated with $1 \mu \mathrm{g} / \mathrm{mL} \mathrm{CuO}$ and $1 \mathrm{mM}$ NAC for up to $24 \mathrm{~h}$ in the absence $(\mathbf{A}-\mathbf{D}, \mathbf{F})$ or presence $(\mathbf{E})$ of the pan-caspase inhibitor z-VAD $(50 \mu \mathrm{M}, 4 \mathrm{~h})$, then washed and stained with annexin V-FITC/PI (A-E) or lysed in the PI/cell cycle buffer (F) followed by flow cytometry. (G) Immunoblotting with K562 cells. See the Materials and Methods (Section 4) and text for details.

To evaluate the plasma membrane integrity in HCT116 cells treated with $\mathrm{CuO}+\mathrm{NAC}$, we used laser confocal microscopy. Pht served as a reference compound since photoactivation of tetrapyrrolic compounds is known to trigger primary loss of plasma membrane integrity $[26,27]$. Accordingly, microscopic laser illumination of Pht loaded cells during imaging resulted in PI influx within the initial 3-5 min (Figure S1). In contrast, PI staining of cells treated with $1 \mu \mathrm{g} / \mathrm{mL} \mathrm{CuO}$ together with $1 \mathrm{mM}$ NAC developed slower; however, by $2 \mathrm{~h}$, intracellular PI fluorescence was detectable (Figure S1), indicating rather fast damage of the plasma membrane. No PI entry was detectable after the addition of $\mathrm{CuO}$ or NAC alone (not shown). Next, activation of caspase 3 was determined by neither by immunoblotting (Figure 3G) nor immunostaining (Figure S2). No proteolytic processing of poly(ADPribose)polymerase (PARP) was observed upon cell exposure to $\mathrm{CuO}+\mathrm{NAC}$, whereas the reference compounds Dox or PF-114, a Bcr-Abl inhibitor [28], induced cleavage of PARP and caspase 3 in K562 cells (Figure 3G and Figure S2). Altogether, we interpreted the complex mode of cell death by $\mathrm{CuO}+\mathrm{NAC}$ as a caspase-independent apoptosis coupled with an early necrosis.

2.3. A Combination of Copper-Containing Compounds and the Reducing Agent Is the Requirement for Cell Sensitization

The above experiments demonstrated the cytotoxic potency of the combination of $\mathrm{CuO}$ NPs and NAC. We were interested in determining whether cell sensitization can be accomplished with different agents (inorganic or organic) that contain copper or other metals. In addition, we aimed to answer the following research question: can $\alpha$-tocopherol 
or ascorbate replace NAC in combinations? The efficacy of sensitization by NAC was similar for acetate and copper oxide (Figure S3). In contrast, no sizeable sensitization by NAC was achieved with Fe, Mo, $\mathrm{Zn}$, or Co oxides, indicating that $\mathrm{Cu}$ is the preferred metal for this combination. A-Tocopherol had no effect, whereas sodium ascorbate $(80 \mu \mathrm{M})$ significantly potentiated the cytotoxicity of CuO NPs (Figure S3). Furthermore, cysteine demonstrated similar sensitizing potency to that of NAC, whereas neither methionine nor phenylalanine changed $\mathrm{CuO}$ cytotoxicity (Figure S3). Thus, copper (either in the oxide or as free ions) and an appropriate reducing agent are necessary for the efficient cytotoxic combination.

Next, we investigated the role of $\mathrm{Cu}$ ion reduction in the context of the organic complexes. We have previously reported a series of biologically active $\mathrm{Cu}$-organic complexes $[10,29]$. In the present study, we tested the complexes of copper and 5-(2-pyridylmethylene)-2-thioimidazol-4-one (compounds 1, 3, 5) with different oxidation states of $\mathrm{Cu}$ atoms $(+1,+1.5$, +2 ), as well as the respective metal-free organic ligands 2 and 4 . Furthermore, we studied Cu-porphyrin complexes 6, 8, and the metal-free carcasses 7 and 9 in combinations with 1 mM NAC (Scheme 1). As shown in Table 2 and Figure S4, NAC substantially increased the cytotoxic potency of $\mathrm{Cu}$ complexes $\mathbf{1}$ and 3, whereas in cases of metal-free $\mathbf{2}$ and 4, sensitization in the presence of NAC was much less pronounced. Similar results were obtained with combinations of NAC and $\mathrm{Cu}$ porphyrins 6 and 8 vs. metal-free counterparts 7 and 9. Interestingly, fold sensitization for individual $\mathrm{Cu}$ organic compounds varied significantly, with a maximum value of 364.0 achieved for $\mathbf{1}$ (Table 2). Compounds 2, 7 and 9 were virtually non-toxic; their $\mathrm{IC}_{50}$ values were not determined. NAC had no effect on the viability of HCT116 cells in combinations with 2, 7 and 9.

These results strongly suggested that the context for the copper ion, particularly its accessibility to the reducing agent, is critical for the efficacy of cell killing. We used cell-free systems to gain insight into the mechanisms of copper-NAC interaction.

\subsection{Electrophysiological Measurements of Membrane Conductance in the Presence of CuO NPs and NAC}

To investigate the influence of CuO NPs and NAC on the permeability of model lipid membranes, the effects on the ion conductance of planar lipid bilayers made from neutral and negatively charged phospholipids were tested. CuO NPs $(1-4 \mu \mathrm{g} / \mathrm{mL})$ (Figure S5a) and NAC (1 mM), alone or in combination (Figure $4 \mathrm{a})$, had no effect on the ion current fluctuations through electrically neutral POPC bilayers. Furthermore, CuO NPs did not change the conductance of negatively charged POPG membranes (Figure S5b). In contrast, NAC alone triggered brief transmembrane current fluctuations in POPG bilayers. This effect was further augmented by the addition of $\mathrm{CuO}$ NPs, but at relatively high concentrations $(>2 \mu \mathrm{g} / \mathrm{mL}$ ) (Figure $4 \mathrm{~b})$.

Table 2. Sensitization of HCT116 cells to $\mathrm{Cu}$-organic compounds by NAC.

\begin{tabular}{|c|c|c|c|}
\hline Compound & No NAC * & $+1 \mathrm{mM}$ NAC * & Fold Sensitization ** \\
\hline 1 & 109.2 & 0.3 & 364.0 \\
\hline 3 & 6.9 & 0.5 & 13.8 \\
\hline 4 & 6.3 & 3.1 & 2.0 \\
\hline 5 & 4.2 & 0.6 & 7.0 \\
\hline 6 & 759.0 & 37.4 & 20.3 \\
\hline 8 & 474.5 & 44.4 & 10.7 \\
\hline
\end{tabular}

${ }^{*} \mathrm{IC}_{50}(\mu \mathrm{g} / \mathrm{mL})$, mean of 3 experiments with $<10 \%$ error. ${ }^{* *} \mathrm{IC}_{\text {noNAC }} / \mathrm{IC}_{\text {compound }+\mathrm{NAC}}$ ratio. 


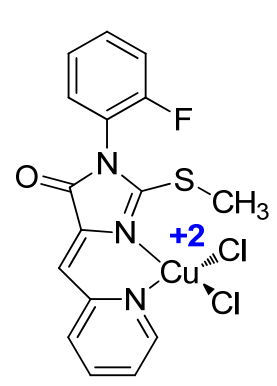

1<smiles>CSC1=NC(=Cc2ccccn2)C(=O)N1c1ccccc1F</smiles>

2<smiles>O=C1/C(=C/c2ccccn2)NC(=S)N1c1ccccc1F</smiles>

4

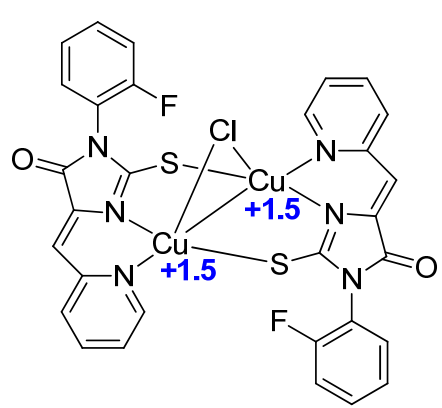

5

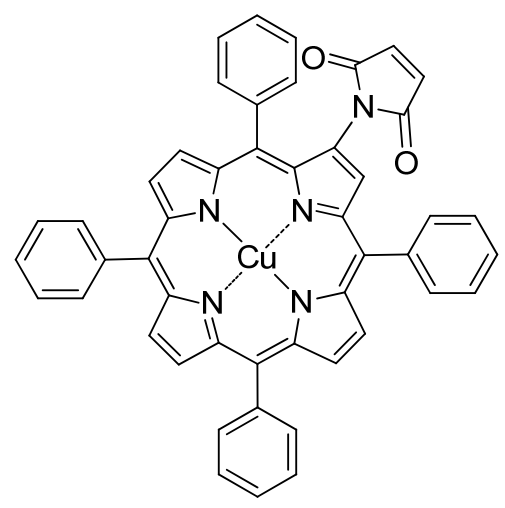

6

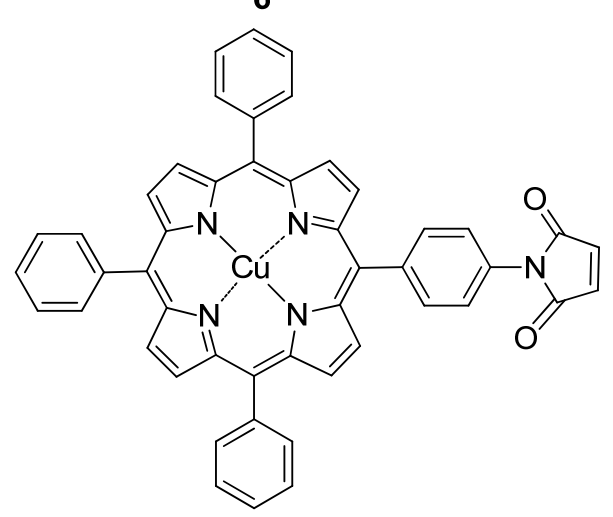

8<smiles>O=C1C=CC(=O)N1C1=CC(c2ccccc2)=NC1=C(c1ccccc1)c1ccc(C(c2ccccc2)=c2ccc(=C(c3ccccc3)c3ccccc3)[nH]2)[nH]1</smiles>

7<smiles></smiles>

9

Scheme 1. Structures of copper organic complexes and the respective metal-free ligands used in the study.

a

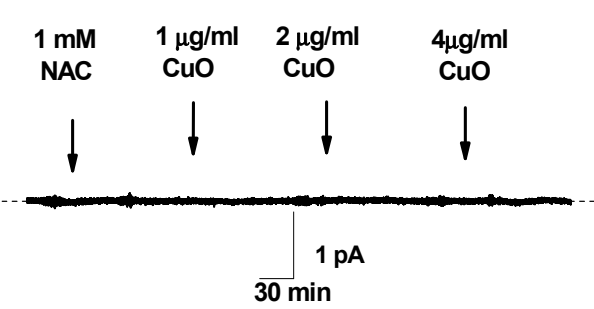

$\mathrm{b}$

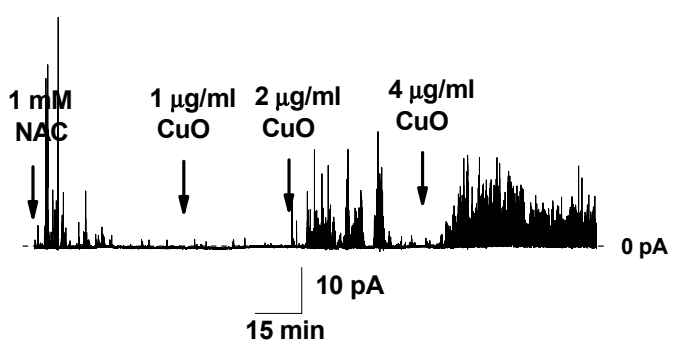

Figure 4. Examples of current fluctuations induced by CuO NPs $(1-4 \mu \mathrm{g} / \mathrm{mL})$ and NAC $(1 \mathrm{mM})$ in lipid bilayers composed of POPC (a) and POPG (b) and bathed in $0.1 \mathrm{M} \mathrm{KCl} \mathrm{pH} \mathrm{7.4.} \mathrm{The} \mathrm{transmembrane} \mathrm{voltage} \mathrm{was} 50 \mathrm{mV}$. Arrows indicate the addition of NAC or CuO NPs into the membrane bathing solution. One experiment out of three replicates with essentially the same results is shown. 


\subsection{Leakage of the Fluorescent Dye from Liposomes Modified by NAC and CuO NPs}

Next, we investigated whether $\mathrm{CuO} N \mathrm{NP}, \mathrm{NAC}$, or their combinations can damage the membranes of unilamellar lipid vesicles by triggering the release of the fluorescent dye calcein. Only a minor leakage of calcein from neutral POPC liposomes was detectable in the presence of $\mathrm{CuO}$ NPs alone or with NAC (IF 6-8\%; Figure 5a). However, unlike $\mathrm{CuO}$ NPs (Figure 5a, black curve) resulting in less than 10\% marker leakage, NAC alone induced calcein release from negatively charged POPG liposomes ( $\mathrm{IF}=18 \%$ ), and this effect was slightly potentiated by $1-4 \mu \mathrm{g} / \mathrm{mL}$ CuO NPs (IF $\sim 25 \%$; Figure $5 \mathrm{~b}$, red curve). These results suggested that NAC directly interacts with negatively charged POPG.
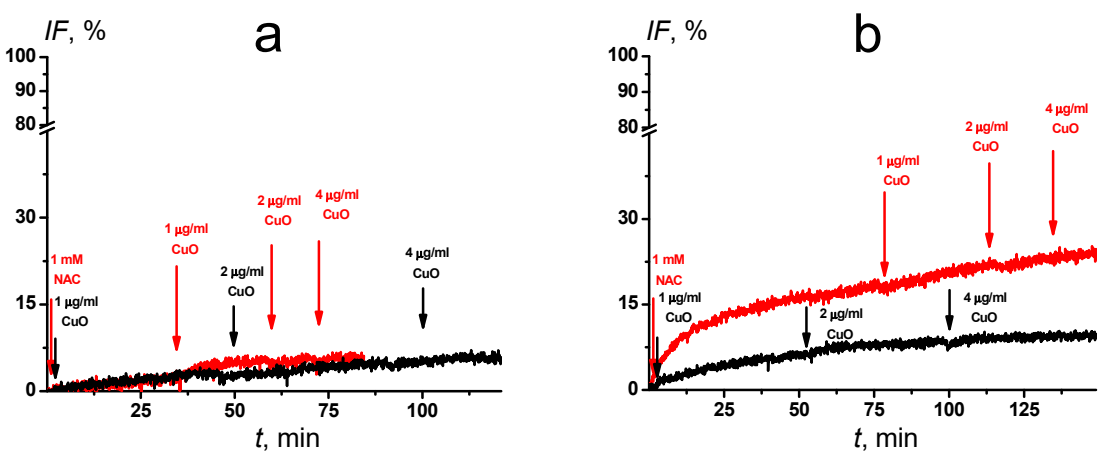

Figure 5. Time dependence of relative fluorescence of calcein (IF, \%) leaked from POPC (a) and POPG (b) vesicles. CuO NPs alone (black curves) or in combination with $1 \mathrm{mM}$ NAC (red curves) were added to the liposomal suspension at indicated concentrations (arrows). One representative experiment out of three independent measurements is shown.

\subsection{DSC of Liposomal Suspensions}

To investigate the effects of CuO NPs and NAC on lipid packing, we performed DSC of liposomes composed of neutral (DPPC) and negatively charged (DPPG) phospholipids with saturated acyl chains. Figure S5 and Table S1 show thermodynamic parameters of DPPC and DPPG liposomes treated with CuO NPs and/or NAC. Each treatment alone or in combination evoked no noticeable changes in thermotropic behavior of neutral DPPC (Figure S6a,c,e). Moreover, $\mathrm{CuO}$ NPs alone did not affect the endotherm of negatively charged DPPG (Figure S6d). In contrast, NAC significantly altered the thermodynamic parameters of DPPG - the main peak corresponding to acyl chain melting was shifted to higher temperatures $\left(\sim 1^{\circ} \mathrm{C}\right.$; Figure S6b), and a deconvolution of the peak was detectable (Figure S6b, inset). The latter observation indicates the presence of lipid phases that varied in the content and structure due to demixing the lipid and NAC. This effect was further augmented by the addition of $\mathrm{CuO} \mathrm{NPs}$ - the maximum of main transition was shifted $\left(>2{ }^{\circ} \mathrm{C}\right)$ toward higher temperatures (Figure S6f). The main peak deconvolution was enlarged, demonstrating at least three lipid phases (Figure S6f, inset).

\subsection{Electrochemical Monitoring of Copper Redox States in the Presence of NAC or Ascorbate}

To test the possibility of $\mathrm{Cu}^{2+}$ reduction, we studied the reactions of the reducing agents NAC or ascorbate with CuO NPs, as well as with organic complex 1 (Figure 6), which contained one copper ion at $\mathrm{Cu}^{+2}$ oxidation state. Reactions were assessed by cyclic voltammetry $(\mathrm{CV})$ and rotating disk electrode $(\mathrm{RDE})$ techniques. 


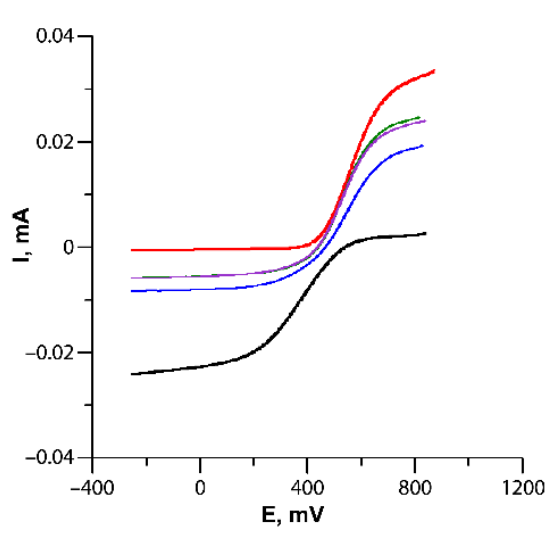

(A)

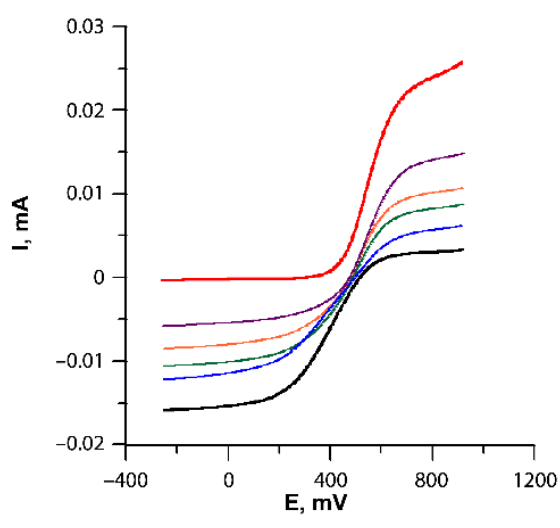

(B)

Figure 6. Voltammograms (RDE) of $\mathrm{Cu}^{+2}$ reduction in complex 1. (A) Mixtures of $\mathbf{1}$ and NAC in a 1:1 ratio registered successively within 25 min after mixing the reagents (blue, violet, and green curves); registered 5 min after mixing of $\mathbf{1}$ and NAC in a 1:3 ratio (red). (B) Mixtures of $\mathbf{1}$ and ascorbate in a 1:1 ratio registered successively within $100 \mathrm{~min}$ after mixing the reagents (blue, orange, green, and violet); registered 40 min after mixing $\mathbf{1}$ and ascorbate in a 1:3 ratio (red). Black, compound $\mathbf{1}$ alone.

The RDE voltammogram allows one to identify the redox transition states of metals. For $\mathrm{Cu}^{+1}$-containing compounds, only the oxidation current was observed (anodic process $\mathrm{Cu}^{+1} \rightarrow \mathrm{Cu}^{+2}$ ), whereas for $\mathrm{Cu}^{+2}$-containing compounds, the reduction current was observable (cathodic reaction $\mathrm{Cu}^{+2} \rightarrow \mathrm{Cu}^{+1}$ ). For mixtures containing $\mathrm{Cu}^{+1} / \mathrm{Cu}^{+2}$, the voltammograms showed both anodic and cathodic currents. Voltammograms were recorded at $960-250 \mathrm{mV}$, corresponding to a $\mathrm{Cu}^{+2}-\mathrm{Cu}^{+1}$ transition in $\mathbf{1}$.

In RDE experiments within this range of electric potential, the solution of $\mathbf{1}\left(\mathrm{Cu}^{2+}\right)$ revealed only a cathode wave (negative current values) corresponding to the electrochemical reduction of $\mathrm{LCu}^{2+} \rightarrow \mathrm{LCu}^{1+}$ (Figure 6A,B, black curves). When NAC or ascorbate was added (1:1 molar ratio), the cathodic current decreased, while the anodic current increased in terms of the voltammograms recorded after $5 \mathrm{~min}$, which indicates a chemical reduction of $\mathrm{Cu}^{2+}$ to $\mathrm{Cu}^{1+}$ by NAC or ascorbate (Figure $6 \mathrm{~A}, \mathrm{~B}$, blue, green, orange, and violet curves). The value of the cathodic current reflects the fraction of the non-reduced (initial) complex $\mathrm{LCu}^{+2}$ in the solution, whereas the value of the anodic current reflects the portion of the reduced $\mathrm{LCu}^{+1}$ at a particular time.

In the reaction of 1 with NAC at 1:1, the equilibrium was established after $25 \mathrm{~min}$ at an anodic current/cathodic current ratio of 5:1. With a threefold excess of NAC, a wave with completely positive current values was observed after $5 \mathrm{~min}$, which corresponds to the oxidation process formed in the solution of the complex with monovalent copper $\mathrm{LCu}^{+1} \rightarrow \mathrm{LCu}^{+2}$, where $\mathrm{L}$ is the organic ligand (Figure $6 \mathrm{~A}$, red curve).

When 1 interacted with ascorbate in a 1:1 ratio, the reduction of $\mathrm{Cu}^{+2}$ to $\mathrm{Cu}^{+1}$ in the complex proceeded slower; an anodic current/cathodic current equilibrium 3:1 was established after $100 \mathrm{~min}$. With an ascorbate/1 ratio of 3:1, the full $\mathrm{LCu}^{+2}$ reduction occurred within $40 \mathrm{~min}$ (Figure $6 \mathrm{~B}$ ). In the reduction of $\mathrm{Cu}^{+2}$ into $\mathrm{Cu}^{+1}$, NAC oxidation is a one-electron process, and ascorbate oxidation is a two-electron process; nevertheless, reduction of $\mathrm{Cu}^{+2}$ with ascorbate proceeded slower than reduction by NAC. Apparently, differential reaction rates in the presence of NAC or ascorbate indicate different mechanisms of oxidation of individual reducing molecules. Thus, NAC and ascorbate at a threefold excess completely reduced $\mathrm{Cu}^{+2}$ to $\mathrm{Cu}^{+1}$ in the solution of $\mathbf{1}$ within a short time.

The $\mathrm{Cu}^{+2}$ to $\mathrm{Cu}^{+1}$ reduction in the presence of NAC was observed using RDE. For the suspension of $\mathrm{CuO} \mathrm{NPs}$, this process was studied in a dimethylformamide/water mixture. However, in this heterogenous system, the effect was less noticeable due to a low intensity of anodic and cathodic currents. 


\subsection{Analysis of $\mathrm{Cu}^{+2} / \mathrm{NAC}$ Interaction by Mass Spectroscopy}

To test the hypothesis about the participation of NAC in the redox reaction with copper( +2$)$, we carried out an investigation of the reaction mixture that formed when mixing the indicated reducing agent with complex 1 , in which the formation of a copper $(+1)$ complex was determined by the RDE examination. The two main peaks in the LC-MS mass spectra of the mixture obtained by the reaction of $\mathbf{1}$ with NAC are attributable to the initial ligand and to the oxidation product of NAC to the corresponding disulfide (a peak with a mass of 325 in positive ions and 323 in negative ions; Figures S7 and S8).

No copper-containing compounds were detected by mass spectroscopy; the reduction products and the initial complex are likely to fall apart on the column, which is often observed for coordination compounds. Thus, the reaction of the $\mathrm{Cu}^{+2}$ complex with NAC can be represented as shown in Scheme 2, top panel. Most likely, the reaction proceeded in the coordination sphere of copper with the initial substitution of thiol group for one of the chloride anions followed by intramolecular electron transfer from $\mathrm{S}$ to $\mathrm{Cu}$ atoms, elimination of the sulfur-centered radical from copper, and dimerization of this radical to disulfide (Scheme 2, bottom panel).

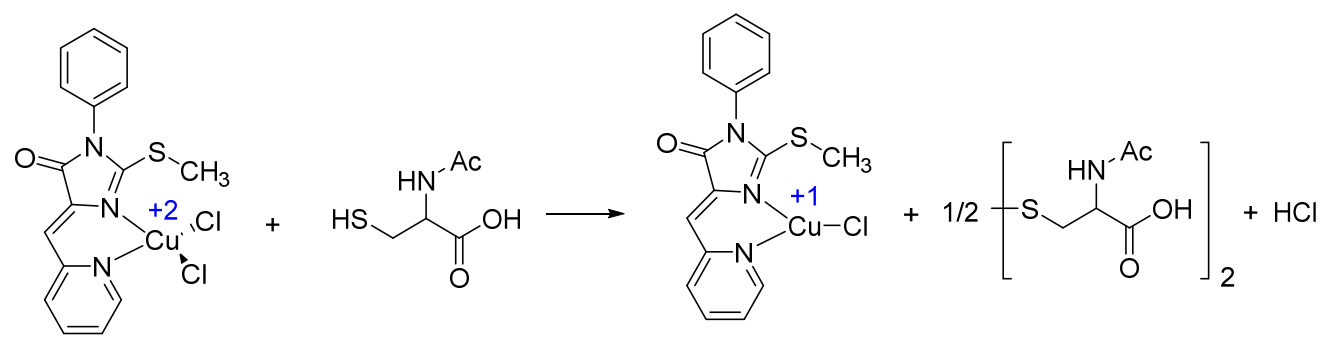

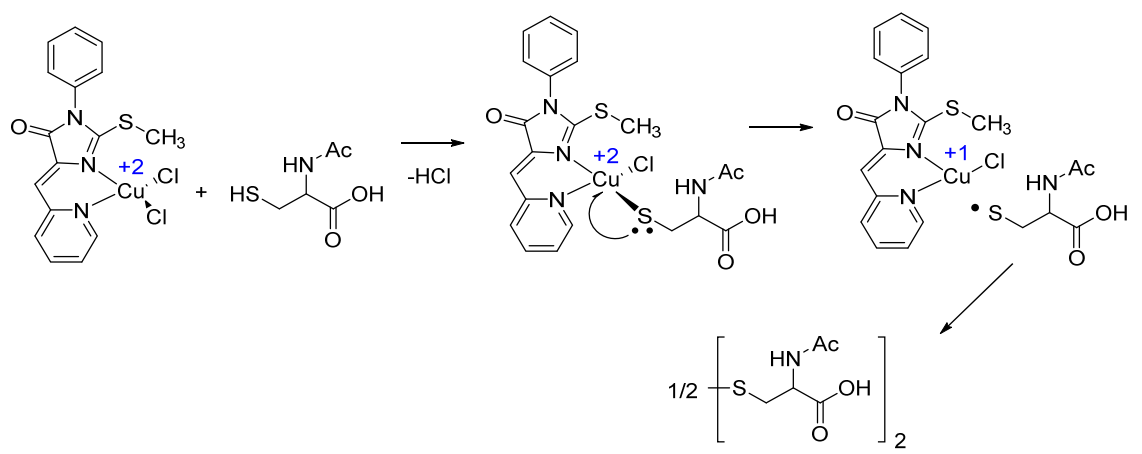

Scheme 2. Molecular transformations during stepwise reduction of $\mathrm{Cu}^{2+}$.

It is also possible, although less likely, that the reaction proceeded intermolecularly without intermediate entry of NAC into the coordination sphere of the copper atom. Thus, NAC oxidation was observed to occur upon interaction with $\mathrm{Cu}^{2+}$-containing complex 1 . The sulfur atoms became no longer available for copper reduction as determined by disappearance of SH groups (detectable with the Ellman's reagent; Figure S9) upon the addition of NAC to CuO NPs.

Finally, LC-MS analysis of the reaction mixture, NAC-CuO NPs, demonstrated essentially the same results as those of NAC + complex 1. At a molar ratio of NPs/NAC 1:1 (No. 1), the intensity of the peak 325 (disulfide) was only minor, whereas at a molar ratio 1:3 (No. 2), this value was 50\%. If NPs/NAC ratio molar was 1:10 (No.3), peak 325 was $4 \%$, whereas the major (80\%) peak was attributed to mass 437 (disulfide $325+$ copper 64 $+\mathrm{CH}_{2} \mathrm{SH} 49$ (Figures $\mathrm{S} 10$ and S11)). These results indicated that at a 10-fold NAC excess, all of the copper was in an ionic form, and these ions were coordinated by the products generated in the process of reduction. 


\section{Discussion}

We demonstrated that the combinations of copper-containing inorganic compounds ( $\mathrm{CuO}$ NPs or $\mathrm{Cu}$ salts) as well as $\mathrm{Cu}$-organic complexes with NAC or ascorbate were remarkably cytotoxic for human tumor cell lines, including the variants with the determinants of anticancer drug resistance. Importantly, each component alone evoked little-to-no activity, whereas together, the effect of potentiation was dramatic. Death as a result of the combinations was observed for a variety of cell lines regardless of the tissue origin and was accompanied by rapid (within the initial hours) ROS generation followed by plasma membrane perturbations, such as disappearance of the phosphatidylserine gradient across the membrane (annexin V reactivity) and loss of integrity (PI influx). Cell death was independent of caspase activation or PARP cleavage, strongly suggesting that the plasma membrane (and perhaps other cellular membranes) was the key target of the combinations. These findings are in line with the recently demonstrated efficacy of the combination of $\mathrm{Cu}$ (II)-containing compounds and ascorbate in inducing cell cycle perturbation and death via oxidative damage of biomacromolecules [19].

Among a panel of tested metals ( $\mathrm{Zn}, \mathrm{Mo}, \mathrm{Fe}$, and $\mathrm{Co}), \mathrm{Cu}$ was the only one that evoked cytotoxicity in combination with NAC or cysteine. Phenylalanine, an amino acid that lacks the $\mathrm{SH}$ group at the $\mathrm{C} 3$ position, was without effect, suggesting the critical role of sulfur. Importantly, the $S$ atom required a specific molecular context, because the $\mathrm{S}$-methyl containing the amino acid methionine did not synergize with $\mathrm{CuO}$. Nevertheless, the $S$ atom was not mandatory since the sulfur-free ascorbate had similar effect to that of $\mathrm{NAC}$, despite being somewhat less pronounced. Altogether, these results point to $\mathrm{Cu}^{2+}$ transformation as a mechanism of cell killing.

Electrochemical studies revealed that NAC or ascorbate reduced divalent copper into a monovalent and then into an uncharged state. In cell-free systems, this process depended on the ratio of $\mathrm{Cu}^{2+}$ and the reducing agent; $40-100 \mathrm{~min}$ were sufficient for the complete transition of the Cu atom's electric charge to zero. One may hypothesize that reduction took place in the coordination sphere of copper and included the substitution of the $\mathrm{SH}$ group for $\mathrm{Cl}^{-}$followed by intramolecular electron transfer from $\mathrm{S}$ to $\mathrm{Cu}$ atoms and elimination of the S-centered radical from the $\mathrm{Cu}$ atom. At the final step, this radical dimerized into disulfide; $S$ atoms became no longer available for copper reduction.

Furthermore, NAC reduced the charge of $\mathrm{Cu}$ cations in the context of copper-organic complexes. The presence of the metal was necessary for tumor cell sensitization since NAC showed a weak, if any, effect in combination with $\mathrm{Cu}$-free organic ligands. Importantly, this efficacy significantly differed depending on the molecular environment of the copper ion. As shown in Table 2, the effect of the combination of NAC and compound $\mathbf{1}$ was much stronger than that of compound $\mathbf{2}+\mathrm{NAC}$ or compound $\mathbf{5}+\mathrm{NAC}$. This difference can be attributed to the +2 oxidation state of $\mathrm{Cu}$ ion in $\mathbf{1}$ coordinated by monodentate chloride anions in addition to the organic ligand. Complexes 3 and 5 contain copper ions in the oxidation states +1 and +1.5 , respectively. Furthermore, in 6 and 8 , copper is tightly coordinated by the tetradentate porphyrin ligand. It can be assumed that, to trigger ROS upon $\mathrm{Cu}$ reduction, the coordination compound must fit the following structural requirements: (1) a Cu ion in the complex must be in the +2 oxidation state, and (2) at least one monodentate ligand capable of maintaining the form of a stable anion after reduction must be present.

Electrochemical modifications of $\mathrm{Cu}$ ions are mechanistically relevant to the generation of oxidative stress via combinations of inorganic or organic $\mathrm{Cu}$-containing compounds with reducing agents. In the presence of oxygen, $\mathrm{Cu}^{+1}$ complexes are capable of generating a superoxide anion that can induce ROS formation in a Fenton-like reaction $\left(\mathrm{Cu}^{+1} \mathrm{~L}+\mathrm{O}_{2}\right.$ $\rightarrow \mathrm{O}_{2}{ }^{-\cdot}+\mathrm{Cu}^{+2} \mathrm{~L}$ ) [30]. We demonstrated intracellular ROS formation within a few hours of exposure to $\mathrm{CuO}$ NPs and NAC. In addition to these results, we did not exclude the possibility of the generation of extracellular ROS by these combinations. Indeed, intracellular accumulation of CuO NPs during $24 \mathrm{~h}$ cell treatment was as low as $\sim 5 \%$ of the initial input as determined by the measurement of copper content in cell lysates by 
atomic force spectroscopy (S.A.T., V.K.Karandashev and A.A.S., unpublished). Moreover, in the experiments with artificial lipid bilayers, we found no significant change in the membrane permeability caused by $\mathrm{CuO}$ NPs in the absence of NAC. The latter agent alone increased the membrane conductance; however, $\mathrm{CuO}$ NPs did not augment this effect. We therefore hypothesized that extracellular ROS may represent a major source of oxidative species for cell damage. This suggestion is in line with the molecular ordering of cell death-associated events in which rapid loss of the plasma membrane integrity was the leading factor. Cell-penetrating $\mathrm{Cu}$-organic complexes might be advantageous over $\mathrm{CuO}$ NPs in terms of water solubility and intracellular accumulation.

Vulnerability to oxidative stress makes the plasma membrane (as well as membrane organelles) an attractive target for elimination of "intractable" tumor cells otherwise irresponsive to apoptotic stimuli [31,32]. We found that CuO NPs + NAC efficiently killed the K562/4 (P-glycoprotein mediated MDR), SCOV-3/CDDP (resistance to cisplatin; [24] and HCT116p53KO (altered response to DNA damaging agents; [25] sublines; the potency of the combination was similar among these sublines and their parental counterparts. However, non-malignant fibroblasts were sensitive to the combination of $\mathrm{CuO}$ NPs and NAC, indicating no cell-type selectivity of the combination.

Nevertheless, the combinations analyzed herein can be applied to advanced disease where conventional treatments usually fail, e.g., for the purge of thoracic or peritoneal cavities from metastatic cells. In these situations, the efficacy of therapies aimed at induction of apoptosis is unlikely; instead, salvage treatment strategies should be considered. The escape of metastatic cells cannot be solely attributed to an impairment of individual death signaling pathways. Mechanisms such as an altered intracellular metal transport can also be advantageous for tumor cell survival. In this scenario, $\mathrm{Cu}$ reduction and ROS generation in the extracellular milieu are perspective for potent and irreversible damage of metastatic cells.

Recently, Wu et al. [33] reported a tumor-specific "non-toxicity-to-toxicity" transition strategy based on hollow mesoporous silica NPs as the carrier. The particles doped with $\mathrm{Cu}^{2+}$ and the FDA-approved drug disulfiram released these components under acidic conditions of the tumor microenvironment. The in situ chelation reaction between the co-released $\mathrm{Cu}^{2+}$ ions and disulfiram generated toxic products. Concurrently, Fenton-like reactions between the generated $\mathrm{Cu}^{+}$ions and $\mathrm{H}_{2} \mathrm{O}_{2}$ resulted in ROS production. This strategy was efficacious against tumor xenografts. Thus, biocompatible materials for targeting tumors with locally controllable cytocidal oxidative burst provide a valuable approach to eradicating intractable malignancies.

In the present study, we used undecorated $\mathrm{CuO}$ NPs, proving their efficacy. Future developments should address the targeted delivery of $\mathrm{Cu}$-containing materials using surface coating with antibodies to identify tumor-specific antigens. Furthermore, given the ability of sulfur to reduce copper in different molecular contexts, the design of supramolecular systems to guide $\mathrm{Cu}^{2+}$ to critical cysteine residues for oxidative destruction of targeted proteins has emerged as a practically important problem.

\section{Materials and Methods}

\subsection{Metal (II)-Containing Agents}

Iron chloride hexahydrate $\left(\mathrm{FeCl}_{3} \cdot 6 \mathrm{H}_{2} \mathrm{O}\right)$, iron (II) sulfate $\left(\mathrm{FeSO}_{4} \cdot 7 \mathrm{H}_{2} \mathrm{O}\right)$, and cobalt nitrate hexahydrate $\left(\mathrm{Co}\left(\mathrm{NO}_{3}\right)_{2} \cdot 6 \mathrm{H}_{2} \mathrm{O}\right)$, as well as other reagents unless specified otherwise, were purchased from Sigma-Aldrich. $\mathrm{CuO}$ NPs were synthesized using the precipitation method [21]. Briefly, $0.5 \mathrm{mg}$ of $\mathrm{CuSO}_{4} \cdot 5 \mathrm{H}_{2} \mathrm{O}$ (Reachim, Saint-Petersburg, Russia) was dissolved in $100 \mathrm{~mL}$ of deionized water to obtain a $10 \mathrm{mM}$ solution, which was heated at $98{ }^{\circ} \mathrm{C}$. Sodium hydroxide (1 M; LenReactiv, Saint-Petersburg, Russia) was added to the mixture under vigorous stirring. The instantly formed black precipitate was washed twice with ethanol and twice with deionized water by pelleting at 12,000 $\mathrm{g}$ for $10 \mathrm{~min}$. The size of the formed NPs was determined by dynamic light scattering (DLS) using a Photocor EPM/Photocor Compact-Z analyzer (Photocor, Moscow, Russia). ZnO NPs were synthe- 
sized using the same procedure as that for $\mathrm{CuO}$ NPs. A solution of $1.5 \mathrm{~g} \mathrm{Zn}\left(\mathrm{NO}_{3}\right)_{2} \cdot 6 \mathrm{H}_{2} \mathrm{O}$ in $60 \mathrm{~mL}$ water was heated to $91^{\circ} \mathrm{C}$ followed by the addition of $1 \mathrm{~mL} 1 \mathrm{M} \mathrm{NaOH}$. Formation of white color indicated the completion of the reaction. Magnetite $\left(\mathrm{Fe}_{3} \mathrm{O}_{4}\right) \mathrm{NPs}$ were synthesized as described [34]. In addition, divalent metal salts $\mathrm{Co}\left(\mathrm{NO}_{3}\right) 2 * 6 \mathrm{H}_{2} \mathrm{O}$ and $\mathrm{MoS}_{2}$ (Alfa Aesar, Ward Hill, MA, USA) were tested. Materials were stored at $4{ }^{\circ} \mathrm{C}$ as dry powders.

\subsection{Cu (II)-Containing Organic Complexes}

Synthesis of Cu-containing organic complexes [(Z)-3-(2-fluorophenyl)-2-methylthio-5(pyridin-2-ylmethylene)-3,5-dihydro-4H-imidazol-4-one]copper(II) dichloride (1; Scheme 1), [(Z)-3-(2-fluorophenyl)-2-methylthio-5-(pyridin-2-ylmethylene)-3,5-dihydro-4H-imidazol4-one]copper(I) chloride (3) and bis[(Z)-3-(2-fluorophenyl)-2-thio-5-(pyridin-2-ylmethylene)3,5-dihydro-4H-imidazol-4-one]copper $(+1.5) \mu$-chloride (5), and corresponding organic ligands [(Z)-3-(2-fluorophenyl)-2-methylthio-5-(pyridin-2-ylmethylene)-3,5-dihydro-4Himidazol-4-one (2) and (Z)-3-(2-fluorophenyl)-2-thio-5-(pyridin-2-ylmethylene)-3,5-dihydro$4 \mathrm{H}$-imidazol-4-one (4) has been reported elsewhere [10].

Synthesis of the Cu complex of 2-(3'-maleimido)-5,10,15,20-tetraphenylporphyrin 6 and the metal free $2-\left(3^{\prime}\right.$-maleimido)-5,10,15,20-tetraphenylporphyrin 7 has been reported in [24]. The copper complex of 5-[ $p$-(3'-maleimido)phenyl]-10,15,20-triphenylporphyrin; compound 8) was synthesized as follows: a solution of $50 \mathrm{mg}(0.25 \mathrm{mmol}) \mathrm{Cu}(\mathrm{OAc})_{2} \cdot \mathrm{H}_{2} \mathrm{O}$ in methanol $(5 \mathrm{~mL})$ was added to a solution $50 \mathrm{mg}(0.07 \mathrm{mmol}) 5$-[ $p$ - $\left(3^{\prime}\right.$-maleimido $)$ phenyl $]$ 10,15,20-triphenylporphyrin 9 in methylene chloride $(5 \mathrm{~mL})$. The resulting mixture was stirred for $1.5 \mathrm{~h}$ at room temperature with TLC monitoring $\left(\mathrm{CHCl}_{3}\right.$-hexane 1:1). Then, the reaction mixture was poured into water and extracted with methylene chloride. The organic layer was dried over $\mathrm{Na}_{2} \mathrm{SO}_{4}$, and the solvent was removed under reduced pressure. Yield $50 \mathrm{mg}\left(93 \%\right.$, dark red solid). UV-Vis $\left(\mathrm{CH}_{2} \mathrm{Cl}_{2}\right) \lambda_{\max },\left(\varepsilon \times 10^{-3}\right) \mathrm{nm}: 419$ (253), 541 (10.7), 577 (2.4). IR (KBr) $v_{\max }, \mathrm{cm}^{-1}: 1719(\mathrm{C}=\mathrm{O}), 1597(\mathrm{C}=\mathrm{C})$. The metal-free 5- $\left(p-\left(3^{\prime}-\right.\right.$ maleimido)phenyl)-10,15,20-triphenylporphyrin (compound 9) was previously synthesized by us [29]. Chemical structures of compounds 1-9 are shown in Scheme 1.

\subsection{Cell Lines and Treatment}

The panel of tumor cell lines included human K562, KU-812, and MOLM-6 chronic myelogenous leukemia; HCT116 colon, SKOV-3 ovarian, MCF-7, and MDA-MB-231 breast carcinomas; and B16F10 murine melanoma (all from American Type Culture Collection (Manassas, VA, USA)). In addition, the isogenic sublines with the molecular determinants of altered drug response were multidrug resistant $M D R 1 / \mathrm{P}$-glycoprotein overexpressing K562/4 subline, HCT116p53KO (non-functional p53) and SKOV-3/CDDP (a 4-fold resistance to cisplatin; gift of G.A.Posypanova, National Research Center 'The Kurchatov Institute', Moscow, Russia) [24,25,35]. Non-malignant hFB-hTERT6 skin fibroblasts were obtained via a lentiviral transduction of the full-length TERT gene under a cytomegalovirus promoter (gift of E. Dashinimaev, Engelhardt Institute of Molecular Biology, Moscow). Cells were maintained in RPMI-1640 (K562, K562/4, KU-812, and MOLM-6) or Dulbecco mediated Eagle's medium (other cell lines) supplemented with $10 \%$ fetal bovine serum (HyClone, Logan, UT, USA) and $50 \mu \mathrm{g} / \mathrm{mL}$ gentamicin at $37{ }^{\circ} \mathrm{C}, 5 \% \mathrm{CO}_{2}$ in a humidified atmosphere. The freshly prepared aqueous suspensions of inorganic materials (see above) were added to the cell-free systems or cell cultures. Copper organic complexes and the respective metal-free organic ligands were dissolved in dimethyl sulfoxide (10 mM). Aqueous solutions were prepared on the day of experiments. N-acetylcysteine (NAC) and cysteine were dissolved in culture media at $50 \mathrm{mM}$ stock solutions, and then $\mathrm{pH}$ was adjusted to 7.2-7.4 with $1 \mathrm{M} \mathrm{NaOH}$. Stock solutions of sodium ascorbate $(500 \mathrm{mM})$ and $\alpha$-tocopherol (250 $\mathrm{mM}$ ) were prepared in water or used as oil, respectively. The pan-caspase inhibitor N-benzyloxycarbonyl-Val-Ala-Asp(O-Me) fluoromethyl ketone (z-VAD-FMK) was from Selleckchem, Houston, TX, USA. The cytotoxicity of metal NPs and Cu-organic 
complexes alone or in combinations with NAC, ascorbate, or $\alpha$-tocopherol was determined in MTT assays [36].

\subsection{Cell Fluorescence}

Cell associated fluorescence was recorded on a CytoFlex flow cytometer (Beckman Coulter, Brea, CA, USA). At least 10,000 events were collected per sample. Data were analyzed using CytExpert software (Beckman Coulter).

\subsection{Time Course of Cell Death}

$\mathrm{CuO}$ NPs $(0.1 \mu \mathrm{g} / \mathrm{mL})$ and NAC $(1 \mathrm{mM})$ were added to the K562 cells in 24-well plates $\left(5 \times 10^{4}\right.$ per well in $1 \mathrm{~mL}$ medium). Every hour, cell aliquots were collected and incubated with propidium iodide (PI; $10 \mu \mathrm{g} / \mathrm{mL}$ ) for $2 \mathrm{~min}$ in the dark. The intensity of fluorescence was measured in the phycoerythrin (PE) channel (585/42 nm).

\subsection{Annexin V-FITC/PI Staining}

K562 cells were plated into 6-well plates (Eppendorf; $2 \times 10^{5}$ cells/well) and treated with the combination of CuO NPs $(0.1 \mu \mathrm{g} / \mathrm{mL})$ and NAC $(1 \mathrm{mM})$ for $4-24 \mathrm{~h}$. Then, cells were stained with annexin V-FITC for $15 \mathrm{~min}$ at room temperature, washed with PBS, and counterstained with $10 \mu \mathrm{g} / \mathrm{mL}$ PI (Dead Cell Apoptosis Kit for flow cytometry; Thermo Fisher Sci., Waltham, MA, USA). Fluorescence intensity was detected in FITC (525/40 nm) and PE channels.

\subsection{Cell Cycle Distribution}

K562 cells $\left(2 \times 10^{5}\right)$ were plated into 6-well plates overnight and then treated with $0.1 \mu \mathrm{g} / \mathrm{mL} \mathrm{CuO} \mathrm{NPs} \mathrm{and} 1 \mathrm{mM}$ NAC for $6 \mathrm{~h}$ or $24 \mathrm{~h}$. Cells were pelleted and lysed in the buffer containing $50 \mu \mathrm{g} / \mathrm{mL}$ PI, $0.1 \%$ sodium citrate, $100 \mu \mathrm{g} / \mathrm{mL}$ RNase A, and $0.3 \%$ NP-40 for $30 \mathrm{~min}$ in the dark. Fluorescence was detected in the PE channel.

\subsection{Mitochondrial Transmembrane Potential}

The MitoTracker ${ }^{\mathrm{TM}}$ Red CMXRos (Thermo Fisher Sci.) was used to monitor the mitochondrial potential. K562 cells were treated with a combination of CuO NPs $(0.1 \mu \mathrm{g} / \mathrm{mL})$ and $1 \mathrm{mM}$ NAC for 4-24 h. The MitoTracker (final concentration $85 \mathrm{nM}$ ) was added to the cells 30 min prior to the completion of treatment. Then, the cells were washed with cold PBS and analyzed in the allophycocyanin (APC) channel $(660 / 10 \mathrm{~nm})$.

\subsection{ROS Detection}

The 6-carboxy-2', $7^{\prime}$-dichlorodihydrofluorescein diacetate (carboxy- $\mathrm{H}_{2} \mathrm{DCFDA}$ ) dye (Thermo Fisher Sci.) was used to detect intracellular ROS. K562 cells $\left(2 \times 10^{5}\right.$ in $1 \mathrm{~mL}$ of medium) were treated with $5 \mu \mathrm{M}$ carboxy- $\mathrm{H}_{2}$ DCFDA for $30 \mathrm{~min}$, washed, and resuspended in fresh medium. $\mathrm{CuO}(1 \mu \mathrm{g} / \mathrm{mL}), \mathrm{NAC}(1 \mathrm{mM})$, or their combination was added to corresponding tubes, and cells were incubated at $37^{\circ} \mathrm{C}, 5 \% \mathrm{CO}_{2}$ for $1-4 \mathrm{~h}$. Cell associated fluorescence of carboxy- $\mathrm{H}_{2}$ DCFDA was measured by flow cytometry in the FITC channel. Ten thousand events were collected per sample. Values of mean fluorescence intensities were normalized by the respective values in untreated (DCFDA alone) cells.

Laser scanning confocal microscopy was used to visualize the morphology of mitochondria and to monitor the integrity of the plasma membrane upon treatment with $\mathrm{CuO}$ NPs and NAC. The HCT116 cells were plated on $35 \mathrm{~mm}$ dishes with the glass bottom (SPL Life Sci., Gyeonggi-do, Korea) and incubated for $72 \mathrm{~h}$ at $37{ }^{\circ} \mathrm{C}, 5 \% \mathrm{CO}_{2}$ to reach $50 \%$ confluence. Then, the cells were incubated with $\mathrm{CuO}$ NPs $(1 \mu \mathrm{g} / \mathrm{mL})$ and NAC (1 mM) for $1-24 \mathrm{~h}$ followed by washing with PBS. Photolon $(10 \mu \mathrm{M}, 3 \mathrm{~h}$, illumination at $660 \mathrm{~nm}, 33 \mathrm{~J} / \mathrm{cm}^{2}$ ) was a reference compound for light-activated oxidative stress and rapid organelle damage, a property of chlorin e6 derivatives [26,37]. For labeling mitochondria and nuclei, dihydrorhodamine 123 (DHR 123; (488 nm/510-570 nm)) and Hoechst 33342 (405 nm/415-470 nm), respectively, were used as recommended by the manufacturer 
(Thermo Fisher Sci.). The entry of PI (488 nm/550-600 nm) was used to monitor the plasma membrane integrity. Images were analyzed on a Leica TCS SPE 5 laser scanning confocal microscope with LAS AF software (Leica Microsystems GmbH, Wetzlar, Germany).

\subsection{Immunostaining}

K562 cells were treated with $0.1 \mu \mathrm{g} / \mathrm{mL} \mathrm{CuO} \mathrm{NPs} \mathrm{in} \mathrm{the} \mathrm{absence} \mathrm{or} \mathrm{presence} \mathrm{of} 1 \mathrm{mM}$ NAC for $6 \mathrm{~h}$ and $24 \mathrm{~h}$. After fixation in $0.75 \%$ paraformaldehyde for $15 \mathrm{~min}$ and permeabilization in ice cold methanol for $30 \mathrm{~min}$, cells were washed with PBS and incubated with rabbit antibodies against cleaved caspase 3 and PARP (Cell Signaling, Danvers, MA, USA; 1:1000) for $1 \mathrm{~h}$. After washing with PBS, the secondary goat anti-rabbit antibodies conjugated with AlexaFluor 488 (Thermo Fisher Sci.; 1:1000) were added, and cells were incubated for $1 \mathrm{~h}$ and analyzed by flow cytometry in the FITC channel.

\subsection{Immunoblotting}

The K562 and HCT116 cells in $60 \mathrm{~mm}$ Petri dishes (80\% confluency) were treated with $\mathrm{CuO}$ NPs $(0.1 \mu \mathrm{g} / \mathrm{mL})$ and NAC $(1 \mathrm{mM})$ for $24 \mathrm{~h}$ at $37{ }^{\circ} \mathrm{C}, 5 \% \mathrm{CO}_{2}$. Dox $(0.2 \mu \mathrm{M})$ was used as a reference compound. After the completion of treatment, the cells were lysed in the buffer containing $150 \mathrm{mM} \mathrm{NaCl}, 1 \% \mathrm{NP}-40,0.1 \%$ SDS, $50 \mathrm{mM}$ Tris base $\mathrm{pH} 8.0$, $2 \mathrm{mM}$ phenylmethylsulfonyl fluoride, and protein inhibitor cocktail (Roche) for $30 \mathrm{~min}$ on ice. The protein concentration was evaluated using Bradford reagent. Cell lysates (35 $\mu$ g of total protein) were resolved in 12\% sodium dodecyl sulfate-polyacrylamide gel (SDS-PAGE) at $120 \mathrm{~V}$ for $1.5 \mathrm{~h}$ and transferred onto $0.2 \mu \mathrm{m}$ nitrocellulose membranes (GE Healthcare, Chicago, IL, USA). After blocking with skimmed milk, the membranes were incubated with rabbit antibodies against human cleaved PARP and total or cleaved caspase 3 (Cell Signaling) at $4{ }^{\circ} \mathrm{C}$ overnight, washed, and incubated with secondary goat anti-rabbit antibodies conjugated with horseradish peroxidase (Cell Signaling). Proteins were visualized using the enhanced chemiluminescence reagent and a ChemiDoc MP gel imaging system (BioRad, Hercules, CA, USA).

\subsection{Planar Lipid Bilayer Setup, Recording System, and Mode of Calculations}

Synthetic 1-palmitoyl-2-oleyl-sn-glycero-3-phosphocholine (POPC) and1-palmitoyl-2oleyl-sn-glycero-3-phospho-(1'-glycerol) (POPG) were obtained from Avanti Polar Lipids, Inc. (Pelham, AL, USA). KCl solution (0.1 M) was buffered with 5 mM HEPES, pH 7.4. Bilayer lipid membranes were prepared from POPC or POPG using a monolayer-opposition technique [38] on a 50- $\mu \mathrm{m}$-diameter aperture in a 10- $\mu \mathrm{m}$-thick Teflon film separating cis-and trans-compartments of the Teflon chamber. Experiments were performed in the chambers containing 0.1 M KCl, $5 \mathrm{mM}$ HEPES-KOH pH 7.4. NAC (1 mM) and CuO NPs $(1-4 \mu \mathrm{g} / \mathrm{mL})$ (each agent alone or in combinations) were added to the cis-chamber to mimic the physiologically relevant conditions. $\mathrm{Ag} / \mathrm{AgCl}$ electrodes with $1.5 \%$ agarose $/ 2 \mathrm{M} \mathrm{KCl}$ bridges were used to apply the transmembrane voltage $(V)$ and measure the transmembrane current (I). "Positive voltage" refers to the case in which the cis-side compartment is positive with respect to the trans-side. All experiments were performed at room temperature.

Measurements of electric current were carried out using an Axopatch 200B amplifier (AutoMate Scientific Inc., Berkeley, CA, USA) in the voltage-clamp mode. Data acquisition was performed with a $5 \mathrm{kHz}$ sampling frequency and low-pass filtering at $100 \mathrm{~Hz}$. The current tracks were processed through an 8-pole Bessel $100 \mathrm{kHz}$ filter. Data were digitized by Digidata 1440A and analyzed using pClamp 10 (AutoMate Sci.) and Origin 8.0 (OriginLab Corp., Northampton, MA, USA).

\subsection{Calcein Release from Liposomes}

Large unilamellar vesicles were made from POPC or POPG and loaded with the fluorescent dye calcein ( $35 \mathrm{mM}$ ) using a mini-extruder (Avanti Polar Lipids, Alabaster, AL, USA). At this concentration, calcein fluorescence inside the liposomes is self-quenched. The increase in fluorescence of free calcein in the surrounding media is a measure of the 
disturbance of membrane integrity in the absence and presence of NAC $(1 \mathrm{mM}), \mathrm{CuO}$ NPs $(1-4 \mu \mathrm{g} / \mathrm{mL})$, or their combinations. The fluorescence of released calcein was determined on a Fluorat-02-Panorama spectrofluorometer (Lumex, Saint-Petersburg, Russia) at $\lambda_{\mathrm{ex}}=490 \mathrm{~nm}, \lambda_{\mathrm{em}}=520 \mathrm{~nm}$. The detergent Triton X-100 (at final concentration of $1 \%$ ) was added at the end of experiments for complete disruption of liposomes (referred to full disengagement of the marker from vesicles).

The relative intensity of calcein fluorescence $(I F, \%)$ was calculated as follows:

$$
I F=\frac{I-I_{0}}{I_{\max } / 0.9-I_{0}} \cdot 100 \%
$$

where $I$ and $I_{0}$ are the calcein fluorescence intensities in the presence and absence of NAC $(1 \mathrm{mM}), \mathrm{CuO} \mathrm{NPs}(1-4 \mu \mathrm{g} / \mathrm{mL})$, or their combinations, respectively, and $I_{\max }$ is the maximal fluorescence after treatment of liposomes with Triton X-100. A factor of 0.9 was introduced to account for sample dilution by Triton X-100.

\subsection{Differential Scanning Microcalorimetry (DSC) of Liposomal Suspensions}

Experiments were performed on a $\mu$ DSC 7 EVO microcalorimeter (Setaram, France). Giant unilamellar vesicles were formed from 1,2-dipalmitoyl-sn-glycero-3-phosphocholine (DPPC) or 1,2-dipalmitoyl-sn-glycero-3-phospho-1'-glycerol (DPPG) (Avanti Polar Lipids, Inc. (Pelham, AL, USA) by the electroformation method (standard protocol, 3V, $10 \mathrm{~Hz}, 1 \mathrm{~h}$, $55{ }^{\circ} \mathrm{C}$ ) using the Nanion vesicle prep pro device (Nanion Technologies, Munich, Germany). Final concentrations were $3 \mathrm{mM}, 1 \mathrm{mM}$, and $1-4 \mu \mathrm{g} / \mathrm{mL}$ of DPPC/DPPG, NAC and CuO $\mathrm{NPs}$, respectively. The liposomal suspension was heated at a constant rate of $0.2 \mathrm{C} / \mathrm{min}$. Reversibility of thermal transitions was assessed by reheating the sample immediately after the cooling step from the previous scan. The temperature dependence of the excess heat capacity was analyzed using Calisto Processing (Setaram, Caluire-et-Cuire, France). The thermograms were characterized by temperature of the main phase transition of DPPC or DPPG $\left(T_{m}\right)$, and the half-width of main peak $\left(T_{1 / 2}\right)$ that characterizes the size of the cooperative lipid unit.

\subsection{Electrochemical Measurements of $\mathrm{Cu}$ Redox State}

The electrochemical behavior of $\mathrm{CuO}$ NPs and compounds 1-5 was studied using cyclic voltammetry $(\mathrm{CV})$ and rotating disk electrode (RDE) techniques. An IPC Pro M potentiostat was used for electrochemical studies. The working electrode was a glassy carbon disk $(\mathrm{d}=2 \mathrm{~mm})$, and the reference electrode was $\mathrm{Ag} / \mathrm{AgCl} / \mathrm{KCl}$ (sat.). The auxiliary electrode was a platinum plate, and the supporting electrolyte was $0.1 \mathrm{M} \mathrm{Bu}_{4} \mathrm{NClO}_{4}$ solution in dimethylformamide. The potential sweep rates were $100 \mathrm{mV} / \mathrm{s}$ (CV method) and $20 \mathrm{mV} / \mathrm{s}$ (RDE method). Samples were dissolved in an air-free solvent. All measurements were carried out in a dry argon atmosphere.

\subsection{Mass Spectrometry}

For HPLC analysis, a system with a Shimadzu Prominence LC-20 (Shimadzu Corporation, Kioto, Japan) column and a convection fraction collector connected with a single quadrupole mass spectrometer Shimadzu LCMS-2020 (Shimadzu Corporation, Kioto, Japan) with dual ionization source DUIS-ESI-APCI were used. The analytical and preparative column was Phenomenex Luna $3 \mathrm{u}$ C18 100A.

\subsection{Measurement of Thiol Group Content}

The 5,5-dithiobis(2-nitrobenzoic acid) (DTNB; Ellman's reagent) (Thermo Fisher Sci.) was used to determine the sulfhydryl groups. The solution of $2 \mathrm{mM}$ DTNB in $50 \mathrm{mM}$ sodium acetate was mixed with $1 \mathrm{M}$ Tris base $\mathrm{pH} 8.0(1: 2 v / v)$ to obtain the working solution. The reaction mixture $(400 \mu \mathrm{L})$ contained $100 \mathrm{ng} / \mathrm{mL}$ or $1 \mu \mathrm{g} / \mathrm{mL} \mathrm{CuO} \mathrm{NPs} \mathrm{alone,}$ $1 \mathrm{mM}$ NAC alone or the combinations of each concentration of NPs with NAC. An aliquot $(10 \mu \mathrm{L})$ was immediately transferred into a 96-well plate (Eppendorf), and then $190 \mu \mathrm{L}$ of 
the working solution was added. Values of optical density (OD) at $412 \mathrm{~nm}$ were measured on a Tecan Spark 10M spectrophotometer (Tecan, Mennedorf, Switzerland).

\subsection{Statistical Analysis}

Experiments were carried out in 3-4 replicates. Data are presented as mean \pm SD. Statistical analysis was performed using GraphPad Prism 7 and Microsoft Office Excel software.

Supplementary Materials: The following are available online at https://www.mdpi.com/article/10 .3390/ijms222011065/s1.

Author Contributions: Conceptualization: A.A.S. Data curation, S.A.T., A.A.M. (Anna A. Moiseeva), D.A.G., A.V.S., V.V.T., V.A.O., O.S.O., M.S.D., E.K.B. and A.A.S.; Formal analysis, S.A.T., A.A.M. (Alina A. Markova), S.S.E., O.O.K., A.A.M. (Alina A. Markova), V.A.O., O.S.O., E.K.B. and A.A.S. Investigation, S.A.T., A.A.M. (Anna A. Moiseeva), N.A.A., S.S.E., A.A.M. (Alina A. Markova), A.V.S., D.A.G., O.O.K., A.A.M. (Alina A. Markova), V.M.A., A.V.Z. and V.V.T.; Methodology, S.A.T., A.A.M. (Anna A. Moiseeva), V.M.A., A.V.Z., A.A.M. (Alina A. Markova), V.V.T., V.A.O. and O.S.O.; Project administration, O.S.O., E.K.B., M.S.D. and A.A.S.; Supervision, A.A.S.; Validation, S.A.T., A.A.M. (Anna A. Moiseeva), S.S.E., D.A.G., V.M.A., A.V.Z., M.S.D. and A.A.S.; Visualization, S.A.T., A.A.M. (Alina A. Markova), V.M.A.; Writing-original draft, S.A.T., V.A.O., O.S.O., E.K.B. and A.A.S.; Writing-review \& editing, S.A.T., V.A.O., O.S.O., M.S.D., E.K.B. and A.A.S. All authors have read and agreed to the published version of the manuscript.

Funding: This study was supported in part by the Russian Foundation for Basic Research (Project 19-29-08007).

Institutional Review Board Statement: Not applicable.

Informed Consent Statement: Not applicable.

Data Availability Statement: Not applicable.

Acknowledgments: We are grateful to V. Vinogradov and E. Anastasova (International Institute of Solution Chemistry of Advanced Materials and Technologies, ITMO University) for providing $\mathrm{CuO}$ NPs and thoughtful criticism. Cu-tetrapyrrole derivatives were synthesized with the financial support from Ministry of Science and Higher Education of the Russian Federation using the equipment of Center for Molecular Composition Studies of A.N.Nesmeyanov Institute of Organoelement Compounds, Russian Academy of Sciences.

Conflicts of Interest: Authors declare no conflict of interest.

\section{References}

1. Samiei, M.; Farjami, A.; Dizaj, S.M.; Lotfipour, F. Nanoparticles for antimicrobial purposes in Endodontics: A systematic review of in vitro studies. Mater. Sci. Eng. C 2016, 58, 1269-1278. [CrossRef] [PubMed]

2. Robinson, J.R.; Isikhuemhen, O.S.; Anike, F.N. Fungal-metal interactions: A review of toxicity and homeostasis. J. Fungi 2021, 7, 225. [CrossRef]

3. Ermini, M.L.; Voliani, V. Antimicrobial nano-agents: The copper age. ACS Nano 2021, 15, 6008-6029. [CrossRef] [PubMed]

4. Yang, M.; Li, J.; Gu, P.; Fan, X. The application of nanoparticles in cancer immunotherapy: Targeting tumor microenvironment. Bioact. Mater. 2021, 6, 1973-1987. [CrossRef]

5. Lelièvre, P.; Sancey, L.; Coll, J.-L.; Deniaud, A.; Busser, B. The multifaceted roles of copper in cancer: A trace metal element with dysregulated metabolism, but also a target or a bullet for therapy. Cancers 2020, 12, 3594. [CrossRef] [PubMed]

6. Skeeters, S.S.; Rosu, A.C.; Divyanshi, J.; Yang, J.; Zhang, K. Comparative determination of cytotoxicity of sub-10 nm copper nanoparticles to prokaryotic and eukaryotic systems. ACS Appl. Mater. Interfaces 2020, 12, 50203-50211. [CrossRef]

7. Zou, L.; Cheng, G.; Xu, C.; Liu, H.; Wang, Y.; Li, N.; Fan, X.; Zhu, C.; Xia, W. Copper nanoparticles induce oxidative stress via the heme oxygenase 1 signaling pathway: In vitro studies. Int. J. Nanomed. 2021, 16, 1565-1573. [CrossRef]

8. Na, I.; Kennedy, D.C. Size-specific copper nanoparticle cytotoxicity varies between human cell lines. Int. J. Mol. Sci. 2021, 22, 1548. [CrossRef]

9. Siivola, K.M.; Suhonen, S.; Hartikainen, M.; Catalán, J.; Norppa, H. Genotoxicity and cellular uptake of nanosized and fine copper oxide particles in human bronchial epithelial cells in vitro. Mutat. Res. Toxicol. Environ. Mutagen. 2020, 856-857, 503217. [CrossRef] 
10. Krasnovskaya, O.O.; Guk, D.A.; Naumov, A.E.; Nikitina, V.N.; Semkina, A.S.; Vlasova, K.Y.; Pokrovsky, V.; Ryabaya, O.O.; Karshieva, S.S.; Skvortsov, D.A.; et al. Novel copper-containing cytotoxic agents based on 2-hioxoimidazolones. J. Med. Chem. 2020, 63, 13031-13063. [CrossRef]

11. Esteban, L.I.; Cadavid-Vargas, F.J.; Di Virgilio, L.A.; Etcheverry, B.S. Vanadium, ruthenium and copper compounds: A new class of nonplatinum metallodrugs with anticancer activity. Curr. Med. Chem. 2017, 24, 112-148.

12. Krasnovskaya, O.; Naumov, A.; Guk, D.; Gorelkin, P.; Erofeev, A.; Beloglazkina, E.; Majouga, A. Copper coordination compounds as biologically active agents. Int. J. Mol. Sci. 2020, 21, 3965. [CrossRef]

13. Chen, Z.-F.; Orvig, C.; Liang, H. Multi-target metal-based anticancer agents. Curr. Top. Med. Chem. 2017, 17, 3131-3145. [CrossRef] [PubMed]

14. Icsel, C.; Yilmaz, V.T.; Aydinlik, S..; Aygun, M. New manganese(II), iron(II), cobalt(II), nickel(II) and copper(II) saccharinate complexes of 2,6-bis(2-benzimidazolyl)pyridine as potential anticancer agents. Eur. J. Med. Chem. 2020, 202, 112535. [CrossRef] [PubMed]

15. Sharma, A.; Goyal, A.K.; Rath, G. Recent advances in metal nanoparticles in cancer therapy. J. Drug Target. 2018, $26,617-632$. [CrossRef]

16. Gaetke, L.M.; Chow, C.K. Copper toxicity, oxidative stress, and antioxidant nutrients. Toxicology 2003, 189, 147-163. [CrossRef]

17. Sharma, P.; Goyal, D.; Baranwal, M.; Chudasama, B. Oxidative stress induced cytotoxicity of colloidal copper nanoparticles on RAW 264.7 macrophage cell line. J. Nanosci. Nanotechnol. 2021, 21, 5066-5074. [CrossRef]

18. Wu, L.; Kang, Z.; Qiao, N.; Wang, C.; Tang, Z. Cu-induced mitochondrial dysfunction is mediated by abnormal mitochondrial fission through oxidative stress in primary chicken embryo hepatocytes. J. Trace Elem. Med. Biol. Organ Soc. Miner. Trace Elem. 2021, 65, 126721. [CrossRef] [PubMed]

19. Cai, D.-H.; Zhang, C.-L.; Liu, Q.-Y.; He, L.; Liu, Y.-J.; Xiong, Y.-H.; Le, X.-Y. Synthesis, DNA binding, antibacterial and anticancer properties of two novel water-soluble copper(II) complexes containing gluconate. Eur. J. Med. Chem. 2021, 213, 113182. [CrossRef]

20. Zheng, J.; Lou, J.R.; Zhang, X.X.; Benbrook, D.M.; Hanigan, M.H.; Lind, S.E.; Ding, W.Q. N-Acetylcysteine interacts with copper to generate hydrogen peroxide and selectively induce cancer cell death. Cancer Lett. 2010, 298, 186-194. [CrossRef]

21. Phiwdang, K.; Suphankij, S.; Mekprasart, W.; Pecharapa, W. Synthesis of CuO nanoparticles by precipitation method using different precursors. Energy Proc. 2013, 34, 740-745. [CrossRef]

22. Vasilichin, V.A.; Tsymbal, S.A.; Fakhardo, A.F.; Anastasova, E.I.; Marchenko, A.S.; Shtil, A.A.; Vinogradov, V.V.; Koshel, E.I. Effects of metal oxide nanoparticles on toll-like receptor mRNAs in human monocytes. Nanomaterials 2020, 10, 127. [CrossRef] [PubMed]

23. Ingle, A.P.; Duran, N.; Rai, M. Bioactivity, mechanism of action, and cytotoxicity of copper-based nanoparticles: A review. Appl. Microbiol. Biotechnol. 2014, 98, 1001-1009. [CrossRef] [PubMed]

24. Ol'shevskaya, V.A.; Alpatova, V.M.; Radchenko, A.S.; Ramonova, A.A.; Petrova, A.S.; Tatarskiy, V.V.; Zaitsev, A.V.; Kononova, E.G.; Ikonnikov, N.S.; Kostyukov, A.A.; et al. $\beta$-Maleimide substituted meso-arylporphyrins: Synthesis, transformations, physicochemical and antitumor properties. Dyes Pigment. 2019, 171, 107760. [CrossRef]

25. Shchekotikhin, A.E.; Dezhenkova, L.G.; Tsvetkov, V.B.; Luzikov, Y.N.; Volodina, Y.L.; Tatarskiy, V.V.; Kalinina, A.A.; Treshalin, M.I.; Treshalina, H.M.; Romanenko, V.I.; et al. Discovery of antitumor anthra[2,3-b]furan-3-carboxamides: Optimization of synthesis and evaluation of antitumor properties. Eur. J. Med. Chem. 2016, 112, 114-129. [CrossRef]

26. Ol'shevskaya, V.A.; Zaitsev, A.V.; Petrova, A.S.; Arkhipova, A.Y.; Moisenovich, M.M.; Kostyukov, A.A.; Egorov, A.E.; Koroleva, O.A.; Golovina, G.V.; Volodina, Y.L.; et al. The synthetic fluorinated tetracarboranylchlorin as a versatile antitumor photoradiosensitizer. Dye. Pigment. 2021, 186, 108993. [CrossRef]

27. Kessel, D. Death pathways associated with photodynamic therapy. Med. Laser Appl. 2006, 21, 219-224. [CrossRef]

28. Ivanova, S.E.; Tatarskiy, V.V.; Yastrebova, A.M.; Khamidullina, I.A.; Shunaev, V.A.; Kalinina, A.A.; Zeifman, A.A.; Novikov, N.F.; Dutikova, V.Y.; Chilov, G.G.; et al. PF-114, a novel selective inhibitor of BCR-ABL tyrosine kinase, is a potent inducer of apoptosis in chronic myelogenous leukemia cells. Int. J. Oncol. 2019, 55, 289-297. [CrossRef]

29. Ol'shevskaya, V.A.; Makarenkov, A.V.; Korotkova, N.S.; Kononova, E.G.; Konovalova, N.V.; Kalinin, V.N. Synthesis of carborane conjugates based on the maleimide derivative of 5,10,15,20-tetraphenylporphyrin. Dokl. Chem. 2014, 458, 165-168. [CrossRef]

30. Li, X.; Hao, S.; Han, A.; Yang, Y.; Fang, G.; Liu, J.; Wang, S. Intracellular Fenton reaction based on mitochondria-targeted copper(ii)-peptide complex for induced apoptosis. J. Mater. Chem. B 2019, 7, 4008-4016. [CrossRef]

31. Markowitsch, S.D.; Juetter, K.M.; Schupp, P.; Hauschulte, K.; Vakhrusheva, O.; Slade, K.S.; Thomas, A.; Tsaur, I.; Cinatl, J.J.; Michaelis, M.; et al. Shikonin reduces growth of docetaxel-resistant prostate cancer cells mainly through necroptosis. Cancers 2021, 13, 882. [CrossRef]

32. Krysko, O.; Aaes, T.L.; Kagan, V.E.; D’Herde, K.; Bachert, C.; Leybaert, L.; Vandenabeele, P.; Krysko, D.V. Necroptotic cell death in anti-cancer therapy. Immunol. Rev. 2017, 280, 207-219. [CrossRef]

33. Wu, W.; Yu, L.; Jiang, Q.; Huo, M.; Lin, H.; Wang, L.; Chen, Y.; Shi, J. Enhanced tumor-specific disulfiram chemotherapy by in situ $\mathrm{Cu} 2+$ chelation-initiated nontoxicity-to-toxicity transition. J. Am. Chem. Soc. 2019, 141, 11531-11539. [CrossRef]

34. Anastasova, E.I.; Ivanovski, V.; Fakhardo, A.F.; Lepeshkin, A.I.; Omar, S.; Drozdov, A.S.; Vinogradov, V.V. A pure magnetite hydrogel: Synthesis, properties and possible applications. Soft Matter. 2017, 13, 8651-8660. [CrossRef]

35. Bunz, F.; Hwang, P.M.; Torrance, C.; Waldman, T.; Zhang, Y.; Dillehay, L.; Williams, J.; Lengauer, C.; Kinzler, K.W.; Vogelstein, B.; et al. Disruption of p53 in human cancer cells alters the responses to therapeutic agents. J. Clin. Investig. 1999, 104, 263-269. [CrossRef] [PubMed] 
36. Tikhomirov, A.S.; Litvinova, V.A.; Andreeva, D.V.; Tsvetkov, V.B.; Dezhenkova, L.G.; Volodina, Y.L.; Kaluzhny, D.N.; Treshalin, I.D.; Schols, D.; Ramonova, A.A.; et al. Amides of pyrrole- and thiophene-fused anthraquinone derivatives: A role of the heterocyclic core in antitumor properties. Eur. J. Med. Chem. 2020, 199, 112294. [CrossRef]

37. Van Straten, D.; Mashayekhi, V.; De Bruijn, H.S.; Oliveira, S.; Robinson, D.J. Oncologic photodynamic therapy: Basic principles, current clinical status and future directions. Cancers 2017, 9, 19. [CrossRef] [PubMed]

38. Montal, M.; Mueller, P. Formation of bimolecular membranes from lipid monolayers and a study of their electrical properties. Proc. Natl. Acad. Sci. USA 1972, 65, 3561-3566. [CrossRef] [PubMed] 